\title{
A EXTinÇão da América Latina: Asco
}

\author{
Helano Jader Ribeiro \\ hjcribeiro@gmail.com
}

\section{ASCO OU UMA INDECIDIBILIDADE}

No primeiro livro de ensaios de Silviano Santiago, Uma literatura nos trópicos, o arquiconceito de entre-lugar é posicionado ao lado do trabalho crítico de Jacques Derrida, em Escritura e diferença, e de Michel Foucault, em Arqueologia do saber. Na década de 1970, ao invés de recorrer aos pensadores sociais ou teóricos da literatura, Santiago almejava compreender o lugar ocupado pelo discurso literário latino-americano, em relação ao europeu, não mais a partir da perspectiva de que o europeu seria a fonte e a influência dos textos latino-americanos, mas abordando o modo como o discurso literário latino-americano reescrevia o já escrito. Analisando o método arqueológico de Foucault, vemos que:

Há, em primeiro lugar, um trabalho negativo a ser realizado: libertar-se de todo um jogo de noções que diversificam, cada um à sua maneira, o tema da continuidade. Elas, sem dúvida, não têm uma estrutura conceitual bastante rigorosa; mas sua função é precisa. Assim é a noção de tradição: ela visa a dar uma importância temporal singular a um conjunto de fenômenos, ao mesmo tempo sucessivos e idênticos (ou, pelo menos, análogos); permite repensar a dispersão da história na forma desse conjunto; autoriza reduzir a diferença característica de qualquer começo, para retroceder, sem interrupção, na atribuição indefinida da origem; graças a ela, as novidades podem ser isoladas sobre um fundo de permanência, e seu mérito transferido para a originalidade, o gênio, a decisão própria dos indivíduos. O mesmo ocorre com a noção de influência, que fornece um suporte - demasiado mágico para poder ser bem 
analisado - aos fatos de transmissão e de comunicação; que atribuiu a um processo de andamento causal (mas sem delimitação rigorosa nem definição teórica) os fenômenos de semelhança ou de repetição; que liga, a distância e através do tempo - como por intermédio de um meio de propagação -, unidades definidas como indivíduos, obras, noções ou teorias (FOUCAULT, 2012, p. 3-4).

Silviano se apropria da estrutura, ativa seus binarismos para logo em seguida fugir do modelo de aprisionamento do objeto. Sua tática é de libertação dessa 'origem', ou melhor, matriz, que é o discurso da dicotomia colônia e metrópole, desarticulando, assim, a angústia da influência. Em seu lugar entra a arché, essa origem primeva, traço questionador da linearidade e da normatividade. $\mathrm{O}$ entre-lugar surge, então, como o grito da descontinuidade e do híbrido, ele ocupa o lugar do jogo estratégico de construção e desconstrução, escapa à lógica do fechamento ocidental que circula dentro de uma encruzilhada dicotômica. Este é, pois, um pensamento que se traça pela e na différance. ${ }^{1} \mathrm{O}$ discurso do entre-lugar, ainda, desterritorializa a América Latina para depois reterritorializá-la numa terceira margem. Nessa fissura, nesse entre-espaço nonada, Derrida encontra lugar para sua abertura ou indecidível:

O indecidível não é somente a oscilação ou a tensão entre duas decisões. Indecidível é a experiência daquilo que, 'estranho', 'heterogêneo' à ordem do calculável e da regra, deve entretanto - é dever que é preciso falar - entregarse à decisão impossível, levando em conta o direito e a regra. Uma decisão que não enfrentasse a prova do indecidível não seria uma decisão livre, seria apenas a aplicação programável ou o desenvolvimento contínuo de um processo calculável. Ela seria, talvez, legal, mas não seria justa (DERRIDA, 2010, p. 46-47).

Não se trata aqui de uma América Latina lida como identidade, porque a identidade é fechamento e não abertura, mas sim de um posicionamento dessa mesma América Latina como uma resposta política ao colonialismo, e sua abertura para as singularidades. Silviano Santiago apresenta, dessa forma, algo parecido com o resgate do simulacro proposto por Gilles Deleuze, que embaralha as noções de original e cópia.

Subverter o platonismo não quer dizer negá-lo, mas, sim, apontar nele possibilidades que devem ser resgatadas e lidas de outra forma.

${ }^{1}$ Différance é um jogo com a palavra francesa différer, que tanto pode significar diferir [postergar] em termos diacrônicos, quanto diferenciar, ou seja, voltar-se para uma temporalização, para atividade, para a phoné, para uma origem arcaizante. A linearidade se desprende e se esvai. 
Segundo Foucault, é necessário transgredir o discurso das generalizações para podermos resgatar os simulacros malditos: "Subverter, com Deleuze, o platonismo e se deslocar nele insidiosamente, descer um grau e ir até esse pequeno gesto - discreto, mas moral - que exclui o simulacro" (FOUCAULT, 2008, p. 232). E continua: "Perverter Platão é deslocar-se na direção da maldade dos sofistas, dos gestos rudes dos cínicos, dos argumentos dos estoicos, das quimeras esvoaçantes de Epicuro" (FOUCAULT, 2008, p. 232-233).

Devemos, pois, potencializar o simulacro para poder salvá-lo. A simulação nada mais seria senão o próprio fantasma. O simulacro pertence às profundezas, o fantasma à superfície, esse é o mecanismo de operação do simulacro. Assim, reverter o platonismo significa, na perspectiva de Deleuze, não simplesmente tornar o mundo sensível mais importante que as ideias, mas a aceitação do simulacro, ou seja, é fazer com que ele afirme seus direitos entre as cópias.

Do resgate do simulacro emerge o entre-lugar no texto de Silviano Santiago. Esse arquiconceito, então, passa a significar um movimento de resistência do colonizado em relação à imposição dos valores do colonizador europeu. A América Latina se torna também um espaço de enunciação territorial, locus que impossibilita a clausura da unidade:

A maior contribuição da América Latina para a cultura ocidental vem da destruição sistemática dos conceitos de unidade e de pureza: estes dois conceitos perdem o contorno exato do seu significado, perdem seu peso esmagador, seu sinal de superioridade cultural, à medida que o trabalho de contaminação dos latinos americanos se afirma, se mostra mais e mais eficaz (SANTIAGO, 1978, p. 18, grifos meus).

A América Latina devém, assim, diferença, e sua repetição, ou um ponto de contestação, vontade de revolta, protesto de si mesmo que se realiza dentro da lógica do diferimento derridiano. A tarefa do intelectual ou do escritor do entre-lugar consiste na exposição consciente de suas fontes (sem que lhe reste dívida alguma), para logo em seguida subvertê-las, ou melhor, profaná-las: "Profanar não significa simplesmente abolir e cancelar as separações, mas aprender e fazer delas um uso novo, a brincar com elas" (AGAMBEN, 2007, p. 75).

É objetivo deste artigo, sobretudo, a profanação do escritor austríaco Thomas Bernhard, lançá-lo no entre-lugar do discurso latino-americano. Devemos, pois, mulatizá-lo em nome do indecidível, de modo que ele se torne híbrido, crioulo. Façamo-lo com Asco. 


\section{A EXTINÇÃO DE SAN SALVADOR OU SUA ORIGEM}

Em 1997, é publicado o terceiro livro de Horacio Castellanos Moya, por uma pequena editora de El Salvador. Trata-se de Asco: Thomas Bernhard em San Salvador. Essa escritura, segundo o próprio autor, é um jogo de exercício linguístico que imita o estilo de Thomas Bernhard, através do monólogo alucinante, exagerado e repetitivo.

Thomas Bernhard arma, com frequência, seu discurso de ódio contra a sociedade austríaca e seus políticos. Ele foi um dos maiores traidores do Estado da Áustria, o escritor infame e incômodo em um país, que, segundo ele, ainda se fazia guiar pelo pensamento nacional-socialista. Bernhard representou o papel de enfant terrible, o Nestbeschmutzer, ${ }^{2}$ o insatisfeito filho ilegítimo e neto do fracassado escritor Johannes Freumbichler. Nascido como um outsider e criado por seu avô, herdou o legado de escritor maldito e solitário. Assim, como um escriba marginal, virou-se contra a política da Áustria tornando-se rapidamente persona non grata.

A estética da repetição que faz parte de sua 'arte do exagero' é uma propriedade regular em sua obra. Revelando-se quase monomaníaca, é uma espécie de brincadeira sádica e pueril de Bernhard com o leitor, como fica claro neste trecho retirado do livro Extinção:

Arrasto a Áustria constantemente na lama, dizem essas pessoas, difamo a pátria de maneira mais despudorada, não perco ocasião de atribuir aos austríacos uma mentalidade abjeta, sórdida e nacional-socialista, quando na verdade não haveria traços dessa mentalidade abjeta, sórdida e nacional-socialista na Áustria, como escrevem essas pessoas. A Áustria não era nem abjeta nem sórdida, sempre foi somente bela, escrevem essas pessoas, e o povo austríaco era respeitável (BERNHARD, 200o, p. 16, grifos meus).

Os vocábulos repetidos 'abjeto', 'sórdido' e 'nacional-socialista' só reforçam a memória e marcam um discurso de ódio contra a Áustria. Dessa forma, é possível falar que repetição e rememoração se imbricam com cumplicidade. É o que Lacan lê no texto de Freud, "Recordar, repetir, elaborar". Ele analisa a relação da Wiederholung [repetição] com a Erinnerung3 [rememoração] a partir desse texto e conclui que

${ }^{2}$ Expressão que significa traidor, mas que ao pé da letra poderia ser traduzida por 'o sujador de ninho'. Bernhard foi chamado por muitos críticos que o apontavam como um traidor do Estado da Áustria.

${ }^{3}$ Er-inner-ung [tornar = er; a coisa = ung; interna = inner $=$ internalizar $]$. 
a rememoração seria a repetição em um ponto, onde houvesse lacunas ou falhas do irrepresentável no aparelho psíquico, que não fossem possíveis no universo simbólico do sujeito. A rememoração pode então ser entendida pela elaboração feita pelos fragmentos da memória [restos], ou, a reprodução no âmbito psíquico das experiências e afetos infantis e conflitos esquecidos, responsáveis pelas repressões. A repetição, assim, é muito mais que um recurso estilístico, estético, ela é, também, politicamente ética e eticamente política.

Da mesma forma, Horacio Moya irá desqualificar a política de El Salvador e as pessoas detestáveis daquele país. A tática é a mesma: repetir para não repetir, ou melhor, repetir para 'extinguir':

Os políticos fedem em todos os lugares, Moya, mas aqui, neste país, os políticos são especialmente fedorentos, posso garantir que nunca vi políticos tão fedorentos como os daqui, talvez seja por causa dos cem mil cadáveres que cada um carrega, talvez o sangue desses cem mil cadáveres seja o que faz tudo feder de um jeito tão peculiar, talvez o sofrimento desses cem mil mortos os tenha deixado impregnados com essa maneira particular de feder, me disse Vega (MOYA, 2013, p. 25, grifos meus).

O pulo às memórias do narrador não representa uma volta saudosista de um passado quase perdido, tampouco é restauração do idêntico esquecido, mas é um apelo à diferença, um ensaio extemporâneo de desvelamento de uma suposta origem absoluta - Beginn [começo] fechado e apreensível ou Entstehung [gênese]. Essa origem se revela muito mais através de Ursprung [Ur - primevo; Sprung - pulo], ela pode ser entendida, então, pelo conceito de Walter Benjamin:

\footnotetext{
Origem [Ursprung] - eis o conceito de fenômeno originário transposto do contexto pagão da natureza para os contextos judaicos da história. Agora, nas Passagens, empreendo também um estudo da origem. Na verdade, persigo a origem das formas e das transformações das passagens parisienses desde seu surgimento até seu ocaso, e a apreendo nos fatos econômicos. Estes fatos, do ponto de vista da casualidade ou seja, como causas -, não seriam fenômenos originários; tornam-se tais apenas quando, em seu próprio desenvolvimento - um termo mais adequado seria desdobramento - fazem surgir a série das formas históricas concretas das passagens, assim como a folha, ao abrir-se, desvenda toda a riqueza do mundo empírico das plantas (BENJAMIN, 2006, p. 504).
}

O conceito de origem de Benjamin não deve ser interpretado como a restauração de um momento primordial, em seu âmago, de uma história 
teleológica; ele se opõe não somente ao conceito bíblico de gênesis, ${ }^{4}$ mas também ao de progresso e desenvolvimento linear da história. Ou, revelando a relação com a história, no conhecido "Prefácio epistemológico" em sua Origem do drama trágico alemão, em que Benjamin demonstra seu objetivo filosófico e metodológico:

\begin{abstract}
Mas, apesar de ser uma categoria plenamente histórica, a origem (Ursprung) não tem nada a ver com gênese (Entstehung). "Origem” não designa o processo de devir de algo que nasceu, mas antes aquilo que emerge do processo de devir e desaparecer. A origem insere-se no fluxo do devir como um redemoinho que arrasta no seu movimento o material produzido no processo de gênese. O que é próprio da origem nunca se dá a ver no plano do factual, cru e manifesto. O seu ritmo só se revela a um ponto de vista duplo, que o reconhece, por um lado, como restauração e reconstituição, e por outro como algo de incompleto e inacabado. [...] A origem, portanto, não se destaca dos dados factuais, mas tem a ver com a sua pré- e pós-história. Na dialéctica inerente à origem encontra a observação filosófica o registo das suas linhas mestras. Nessa dialéctica, em tudo o que é essencial, a unicidade e a repetição surgem condicionando-se mutuamente (BENJAMIN, 2004, p. 32).
\end{abstract}

Walter Benjamin irá denominar de salto tigrino ao passado toda apropriação do mesmo não saudosista, mas sim, dialético, de modo que o presente não seja mais o mesmo. Ele propõe outra concepção do tempo que não é o tempo homogêneo e vazio das ciências históricas e naturais. A ideia de progresso histórico é rechaçada e em seu lugar sugere que tomemos o tempo como algo que permite instantes de ruptura, de iluminações contínuas.

Fica sugerido em nossa análise, então, que Moya procura através de um Ur-Sprung [primevo-pulo], como metodologia de leitura da história, retornar à origem ${ }^{5}$ em seu $A s c o$, ou à origem da origem das memórias

${ }^{4}$ Nessa instância, fato que parece paradoxal para o pensamento de Benjamin: a complementaridade da visão materialista da história através da visão messiânica é a explicação para um pensamento que não é transcendente, mas assume um tempo de agora como modelo messiânico que abarca num resumo a história da humanidade. No mundo messiânico, não há uma espécie de télos a ser atingido, mas o que ocorre é essa suspensão do continuum da história.

${ }^{5}$ Nesse sentido, devemos pensar, também, a questão da origem em Moya, a partir da différance de Jacques Derrida, não como uma origem plena, mas sim como o borramento da origem - espaço a ser preenchido em um campo imanente, em que as diferenças jogam. Trata-se aqui de uma origem lida como différance e não como conceito fechado, tampouco como apenas palavra, mas aquela que questiona a autoridade de uma origem absoluta, de um ponto de partida incontestável - um logos supremo, matricial, de onde tudo se origina. 
do narrador, descartando, dessa forma, os ditames progressistas de uma história linear dos eventos. Esse pulo é, assim, aberto e descontínuo, não se deixa fechar por nenhuma tentativa de totalidade. É processo intermitente que impede qualquer modelo de fechamento, revelando-se, dessa forma, como uma escritura enciclopédica ${ }^{6}$ através de sua estética da repetição.

Moya convoca, através do salto, os alijados da história de seu país para a tarefa de escovar a história a contrapelo, mostrando resistência ao progresso, à civilização - e sua barbárie -, ao tempo linear e homogêneo. Essa volta ao passado é uma tentativa sua de restituir as promessas soterradas pelas ruínas, das vozes dos excluídos que ainda clamavam por salvação. Nesse sentido, o messianismo sevolta para trás [para o materialista histórico], permitindo, assim, seu posicionamento para o momento de aqui e agora, tempo em que essas mesmas vozes dos habitantes de San Salvador ainda buscam por redenção: "Por isso, contra a minha vontade, tive que ver e escutar esses políticos que estavam fedendo do sangue de cem mil pessoas [grifo meu] que mandaram matar [...]" (MOYA, 2013, p. 26). Os cem mil cadáveres são as vozes pulsantes dentro do limbo da história que esperam por sua redenção: "A redenção (Erlösung) só pode dar-se a partir do momento em que se faz necessário contar a história dos vencidos" (RAMOS, 2010, p. 69).

Nesse silenciar de vozes sufocadas [cem mil cadáveres = povo] se dá a crise da produção narrativa, que, segundo Benjamin, tinha como sua fonte primária a oralidade: "O grande narrador tem sempre suas raízes no povo, principalmente nas camadas artesanais” BENJAMIN, 1996a, p. 214). As histórias anteriormente contadas oralmente perdem com essa incapacidade do homem pós-guerra de relatar o ocorrido. Sob a égide desse pensamento, analisamos o narrador de Asco como um traumatizado.

Nesse sentido, a análise de Sigmund Freud nos mostra que a questão do trauma está profusamente implicada na compulsão por repetição e, consequentemente, na rememoração. Freud introduziu a chamada 'compulsão à repetição' formalmente na teoria psicanalítica em Além do princípio do prazer [1920]:

Em vista dessas observações feitas a partir do comportamento na transferência a partir do destino dos seres humanos, devemos ter coragem de supor que

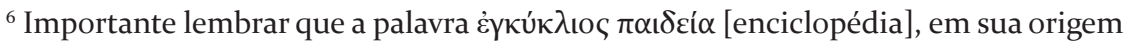
etimológica, significa conhecimento circular.
} 
existe realmente na vida psíquica uma compulsão à repetição que se sobrepõe ao princípio do prazer. Nós também nos inclinaremos agora a relacionarmos a essa compulsão os sonhos dos que padecem de neurose traumática e o impulso para o jogo da criança (FREUD, 2010, p. 183).

Ao se deparar com os sonhos repetitivos de pacientes com neuroses traumáticas, como por exemplo, de guerras, Freud passa a questionar sua teoria dos sonhos, pela qual afirmava que eles seriam uma realização de desejo. Ele analisa sua função, que repetem cenas traumáticas, como dolorosas. Para ele, tais sonhos teriam a função de desenvolver a angústia retroativamente, onde esta faltou. A repetição obsessiva mistura o sentido atribuído às palavras, mas surge na prática psicanalítica como movimento fundamental para o processo de análise, visto que ela também está ligada à transferência. Porque a repetição é uma transferência do passado esquecido, ela atua como força de rememoração de acontecimentos dificilmente observáveis fora da terapia. Mas essa recordação é da ordem do inconsciente, porque somente se repete aquilo que não pode ser lembrado. Quanto maior for a resistência, maior será a força da repetição.

O narrador gagueja e repete os signos linguísticos incansavelmente, mostrando-se, através desse jogo, incapaz de continuar com um relato livre do trauma sofrido por sua família e pela crueldade dos militares em seu país:

[...] todos caminham como se fossem militares, cortam o cabelo como se fossem militares, pensam como se fossem militares, é espantoso Moya, todos querem ser militares, todos seriam felizes se fossem militares, todos adorariam ser militares para matar impunemente, todos carregam o desejo de matar em seu olhar, na maneira de caminhar, no jeito de falar, todos querem ser militares para poder matar, isso significa ser salvadorenho, Moya, querer parecer militar, me disse Vega (MOYA, 2013, p. 21-22, grifos meus).

O relato é focado em Edgardo Vega, acadêmico que retorna ao país para o enterro da mãe. Enquanto espera pela liberação do inventário, Vega expõe para seu interlocutor mudo, ${ }^{7}$ de nome Moya, os males na política e em sua família: "Nunca vi políticos tão ignorantes, tão selvagemente

${ }^{7}$ Semelhante em Extinção e Asco é a participação de um interlocutor mudo: "O norte se tornou totalmente insuportável para mim, Gambetti, disse, quanto mais vou para o norte, mais insuportável se torna para mim [...]" (BERNHARD, 20oo, p. 83). Como bem se vê, também, em Asco: "Não tinha a menor intenção de vir para o velório de minha mãe, Moya, ela sabia disso [...]” (MOYA, 2013, p. 19). 
ignorantes, tão evidentemente analfabetos como os desse país, Moya [...]" (MOYA, 2013, p. 25). Esse é o mesmo fio condutor do romance Extinção: uma derrocada, de Bernhard, a volta, o regresso em função da morte dos pais do narrador Franz-Josef Murau, e a expectativa pela abertura do testamento: "[...] percorrendo toda a extensão do Corso até chegar a meu apartamento, onde por volta das duas da tarde recebi o telegrama que me participava a morte de meus pais e de meu irmão Johannes" (BERNHARD, 2000, p. 7).

Na Extinção de Thomas Bernhard, vê-se o narrador e protagonista Franz-Josef Murau, que odeia sua família e a burguesia austríaca pós-Segunda Guerra Mundial, das quais se afasta para se exilar em Roma. Anos mais tarde, com o mínimo contato com Wolfsegg, lugar onde havia nascido, recebe um telegrama informando sobre a morte dos pais e irmão, causada por um acidente de carro. Retorna, dessa forma, ao lugar de suas origens, mas que já não podia mais ser chamado de Heimat (como, aliás, nunca pôde ser chamado), palavra alemã que designaria em português a noção que temos de pátria. O retorno traduz-se por uma busca de sentido, que é a essência do ser exilado em si mesmo. ${ }^{8}$ Como nos lembra Jean-Luc Nancy: "O retorno significa, portanto, em primeiro lugar, que nada se havia perdido verdadeiramente e que nem a duração da crise, nem da abundância e a intensidade de suas manifestações puderam alterar no fundo certa ideia de sentido" (NANCY, 2003, p. 13). O retorno é o retorno do sentido, mas cruzado a cada instante por um devir louco que não cessa.

Se, de um lado, o narrador de Extinção surge através de um nome fictício, o que caracterizaria esse romance mais próximo da linha do romance autobiográfico, visto que Extinção é sempre atribuído a Bernhard como sua antiautobiografia, do outro lado temos a obra de Moya e o jogo com o nome próprio de forma descarada na narrativa, o que pode ser lido como uma autoficção. De acordo com Diana Klinger:

Concebemos a auto-ficção como um discurso que não está relacionado com um referente extra-textual (como no caso da autobiografia), mas também não está

8 Se fizermos uma alusão à viagem de Ulisses, veremos que o mais importante não é o fato do retorno à origem, mas sim o processo da viagem em si. Cada intervalo de tempo nessa viagem apresenta-se com sua diferença, como se se assemelhasse a um cálculo de limite matemático. Em matemática, o conceito de limite é usado para descrever o comportamento de uma função à medida que seu argumento se aproxima de um determinado valor, sem nunca alcançá-lo, assim como é o comportamento da sequência de números reais, à medida que o índice nessa escala cresce em direção ao infinito. 
completamente desligado dele. A auto-ficção participa da criação do mito do escritor, uma figura que se situa no interstício entre a "mentira" e a "confissão". A noção do relato como criação da subjetividade, a partir de uma manifesta ambivalência a respeito de uma verdade prévia ao texto, permite pensar, como veremos a seguir, a auto-ficção como uma performance do autor (KLINGER, 2006, p. 55).

Na autoficção, o autor 'ficcionaliza', mas joga seu nome próprio descaradamente no texto, não precisando se esconder através de outros nomes. Essa seria a crítica apresentada acima em relação ao romance autobiográfico:

A verdade é que contra o pudor do romance autobiográfico pelos nomes próprios e de referências fora do texto, a autoficção tende para o outro extremo e, sem qualquer consideração para as pessoas envolvidas, oferece-os em profusão, tornando-se assim a denúncia da má consciência do romance autobiográfico (AMÍCOLA, 2009, p. 188). ${ }^{9}$

Trata-se aqui, no entanto, da apropriação consciente de Moya do nome de Thomas Bernhard para a tessitura de seu discurso de ódio, através do martelo crítico já elaborado na escritura de Bernhard. Esse é um dos papéis do escritor latino-americano: a possibilidade reflexiva sobre a política a partir do olhar do outro. Segundo Silviano Santiago:

O texto segundo se organiza a partir de uma meditação silenciosa e traiçoeira sobre o primeiro texto, e o leitor, transformado em autor, tenta surpreender o modelo original nas suas limitações, nas suas fraquezas, nas suas lacunas, desarticula-o e o rearticula de acordo com as suas intenções, segundo sua própria direção ideológica, sua visão do tema apresentado de início pelo original. O escritor trabalha sobre outro texto e quase nunca exagera o papel que a realidade que o cerca pode representar na sua obra. Nesse sentido, as críticas que muitas vezes são dirigidas à alienação do escritor latino-americano, por exemplo, são inúteis e mesmo ridículas. Se ele só fala da sua própria experiência de vida, seu texto passa despercebido dos seus contemporâneos. [...] Nosso trabalho crítico se definirá antes de tudo pela análise do uso que o escritor fez de um texto ou de uma técnica literária que pertence ao domínio público, do partido que ele tira, e nossa análise se completará pela descrição da técnica que o mesmo escritor cria no seu momento de agressão contra o modelo original, fazendo ceder as fundações que o propunham como objeto único e de reprodução impossível (SANTIAGO, 1978, p. 22-23).

9 "Lo cierto es que contra el pudor de la novela autobiográfica por los nombres propios y referenciales hacia el afuera de texto, la autoficción tiende al otro extremo y, sin ninguna consideración por los implicados, los ofrece con profusión, tornándose así como la denuncia de la mala conciencia de la novela autobiográfica." 
Ora, de acordo com esse posicionamento crítico de Silviano Santiago, é possível falar de um olhar poderoso lançado pelo escritor latino-americano que desfaz a noção de original, ou da suposta metrópole. A respeito da 'des-feita' do olhar, pensemos na pintura do deformado Papa Inocêncio $\mathrm{X}$, de Francis Bacon, devorando e reinventando a pintura do mesmo Papa, de Diego Velázquez. O que vemos nos olha de volta, mas olha com terror. Através desse movimento, se dá o fim de uma origem [Beginn], um gênesis, da qual todas as coisas derivariam. Não se trata de cópia da cópia, mas do despertar do terror e do desespero através de uma pintura que interroga, interpela e penetra, cheia de sentido, o trabalho de Velázquez.

Assim o faz Moya. Ele se apropria não somente dos recursos estilísticos de Bernhard, mas, também, faz uso de seu nome próprio, nome este que já aparece como subtítulo da obra. Além disso, ao final do livro, o nome Thomas Bernhard é revelado de outra maneira. Segundo declaração do narrador: "Meu nome é Thomas Bernhard, me disse Vega, um nome que peguei emprestado de um escritor austríaco que admiro e que, com certeza, nem você nem os outros imitadores dessa infame província conhecem" (MOYA, 2013, p. 98).

Sabemos bem, dessa forma, que o nome Thomas Bernhard é contaminado pelo discurso do escritor latino-americano; sua Extinção ganha uma nova vida, ou melhor, sobrevivência, através dessa mesma 'desfeita' do nome próprio. A reprodução, no entanto, não destrói o original, mas impõe uma diluição daquilo que Benjamin chama de aura. A libertação graças à reprodução técnica da obra de arte faz com que o valor do ritual seja substituído pelo valor da exposição, ou seja, possibilita a exibição para qualquer pessoa e para as grandes massas, o que antes só era possível àqueles que tinham o acesso à obra de arte. De acordo com Benjamin:

O conceito de aura permite resumir essas características: o que se atrofia na era da reprodutibilidade técnica da obra de arte é a sua aura. Esse processo é sintomático, e sua significação vai muito além da esfera da arte. Generalizando, podemos dizer que a técnica de reprodução destaca do domínio da tradição o objeto reproduzido. Na medida em que ela multiplica a reprodução, substitui a existência única da obra de arte por uma existência serial. E na medida em que essa técnica permite à reprodução vir ao encontro do espectador, em todas as situações, ela atualiza o objeto reproduzido (BENJAMIN, 1996b, p. 168).

A obra de arte aurática, ainda em seu estágio de culto, possui um sentido baseado na unicidade. Primeiramente ela aparecia como magia, depois era seguida pela religião, o que nos faz concluir que essa obra 
de arte tem um fundo teológico definido. Com o advento da fotografia e, em especial, do cinema, ocorre uma mudança significativa: essa arte reprodutível passa a operar no plano político, visto que, como já foi dito, ela consegue atingir um incrível número de pessoas com base na reprodução de um único 'original'. É aí que passa a residir, para Benjamin, o caráter de trabalho político da estética moderna (ou: da modernidade, a partir de Baudelaire). Benjamin bem sabia que o nazismo se valia dessa nova espécie de obra de arte como uma forma de controle e manipulação das massas.

\section{LITERATURA PÓS-FUNDACIONAL}

Os mitos da fundação da literatura latino-americana não são os mesmos em torno da fundação das literaturas nacionais. De um lado, temos as literaturas nacionais surgidas como nações ao longo do século XIX, de outro, uma literatura latino-americana associada aos anos 1960, época em que a revolução cubana e o despontar da narrativa se uniram para forjar uma imagem da América Latina como um continente culturalmente entrelaçado. Segundo Flora Süssekind, a literatura de fundação é o "Recurso para anunciar uma 'grandeza americana' por vir: esta uma das funções básicas da 'cena profética de fundação’ na literatura produzida durante o período colonial” (SÜSSEKIND, 1994, p. 75). A necessidade de uma literatura de fundação já podia ser observada pelos modernistas brasileiros principalmente através da obra de Mário de Andrade, Macunaíma.

Ao contrário de uma literatura de fundação, modernista, que busca devorar outra cultura, mesclando-a à sua, a literatura pós-fundacional de Moya é uma repetição, de modo que ela mesma é potencializada. Em detrimento da falsificação, entra um simulacro que não pertence nem a um, nem a outro lugar, permanece no 'entre-lugar', ou na América Latina, que representa esse 'entre-lugar'.

A literatura de fundação pressupõe a criação de uma autonomia, chama-se nação de dentro e fora, tupi or not tupi..$^{10}$ Ela mostra a existência de classes

\footnotetext{
${ }^{10}$ Esta é uma apropriação da frase hamletiana [to be or not to be] e um jogo entre linguagens, com referência aos indigentes indígenas. Também por isso mantém sintonia com o gesto da literatura assinada por Moya.
} 
e se revela ontológica ao levantar questionamentos sobre o que é nacional ou o que somos nós, como bem o exemplifica Formação da Literatura Brasileira, de Antonio Candido. A literatura pós-fundacional, por sua vez, preconiza o lema indecidível tupi e não tupi, em que ambas as partes estão incluídas.

A respeito de San Salvador, o narrador Vega declara:

\begin{abstract}
[...] a cidade em si já é uma das cidades mais imundas e hostis que você poderia conhecer, uma cidade desenhada para animais, não seres humanos, uma cidade que transformou o seu centro histórico em um lixão porque ninguém se importa com a história, pois o centro histórico é absolutamente desnecessário e foi transformado em um lixão, de fato, a cidade é um lixão, uma cidade nojenta, comandada por sujeitos obtusos e ladrões cuja única preocupação é destruir qualquer arquitetura que lembre minimamente o passado para construir postos de gasolina Esso, pizzarias e lanchonetes (MOYA, 2013, p. 41).
\end{abstract}

Não se trata aqui de refundação de uma 'origem', mas sim da invenção de uma 'origem' ainda por vir, em sua différance. A origem [Ursprung] não só determina a sobrevivência dessas imagens apontadas pelo narrador, mas também, ao mesmo tempo, esta sobrevivência anárquica a inopera. Ela não é fundação, é pós-fundação. O Anfang [início] como Ursprung [origem] nunca se conclui, está constantemente se dando, revela-se como devir. Nesse movimento, abre-se espaço para as singularidades em um deslumbre dialético. O narrador de Moya vai, dessa forma, à origem, onde se encontra o arquivo, e é na figura de Edgardo Vega que temos a recuperação desse mesmo arquivo. A origem [Ursprung] mesmo sendo um conceito histórico não é o começo de tudo. A origem não aponta a identidade, mas sim, assinala um movimento. Ela não cessa de se produzir, é um processo dinâmico. Moya não deseja apagar o fundamento último, mas faz repensar as figuras metafísicas tradicionais, para ele a origem poderia ser diferente do que foi, de forma que profana a ideia de origem entendida como gênese ou matriz única.

Assim, vemos que Horacio Castellanos Moya arma uma meditação traiçoeira em torno do texto de Bernhard, eleaponta para o modelo original, que, ao mesmo tempo, tem sua aura atingida [diluída], desterritorializa o olhar do outro e o reterritorializa no entre-lugar chamado América Latina. Segundo Silviano Santiago: "O signo estrangeiro se reflete no espelho do dicionário e na imaginação criadora do escritor latino-americano e se dissemina sobre a página branca com a graça e o dengue do movimento da mão que traça linhas e curvas" (SANTIAGO, 1978, p. 23). O signo estrangeiro só serve de munição para a máquina de guerra de nome Asco. 
272 - Remate de Males 36.1

\section{REFERÊNCIAS BIBLIOGRÁFICAS}

AGAMBEN, Giorgio. Elogio da profanação. In: . Profanações. Tradução de Selvino José Assman. São Paulo: Boitempo, 2007.

AMÍCOLA, José. Autoficción, una polémica literaria vista desde los márgenes (Borges, Gombrowicz, Copi, Aira). Revista Olivar, n. 12, 2009.

BENJAMIN, Walter. O narrador. In: . Magia e técnica, arte e política: ensaios sobre literatura e história da cultura. Obras escolhidas, vol. 1. Tradução Sergio Paulo Rouanet. São Paulo: Brasiliense, 1996a.

BENJAMIN, Walter. "A obra de arte na era de sua reprodutibilidade técnica”. In: Magia e técnica, arte e política: ensaios sobre literatura e história da cultura. Obras escolhidas, vol. 1. Tradução Sergio Paulo Rouanet. São Paulo: Brasiliense, 1996b.

BENJAMIN, Walter. Origem do drama trágico alemão. Tradução de João Barrento. Lisboa: Assírio \& Alvim, 2004.

BENJAMIN, Walter. Passagens. Tradução Irene Aron e Cleonice Paes Barreto Mourão. Belo Horizonte: Ed. UFMG; São Paulo: Imprensa Oficial do Estado de São Paulo, 2006.

BERNHARD, Thomas. Extinção: uma derrocada. Tradução de José Mariani de Macedo. São Paulo: Companhia das Letras, 2000.

DERRIDA, Jacques. Força de lei: o fundamento místico da autoridade. Tradução de Leyla Perrone-Moisés. São Paulo: Martins Fontes, 2010.

FOUCAULT, Michel. Teatrum Philosophicum. In: Ditos e escritos. Tradução de Elisa Monteiro. Rio de Janeiro: Forense Universitária, 2008, vol. II.

FOUCAULT, Michel. Arqueologia do saber. Tradução de Luiz Felipe Baeta Neves. Rio de Janeiro: Forense Universitária, 2012.

FREUD, Sigmund. Recordar, repetir e elaborar. In: Obras completas, vol. 10. Tradução de Paulo César Lima de Souza. São Paulo: Companhia das Letras, 2010.

KLINGER, Diana. Escritas de si e escritas do outro: auto-ficção e etnografia na literatura latino-americana contemporânea. Tese de Doutorado. Literatura Comparada. Letras. UERJ, Rio de Janeiro, 2006.

MOYA, Horacio Castellanos. Asco: Thomas Bernhard em San Salvador. Tradução de Antônio Xerxenesky. Rio de Janeiro: Rocco, 2013.

NANCY, Jean-Luc. El olvido de la filosofía. Tradução de Pablo Perera Velamazán. Madri: Arena libros, 2003.

RAMOS, Pedro Hussak van Velthen. O sagrado e o profano em Agamben. In: Walter Benjamin: arte e experiência (org.: Luis Sérgio de Oliveira e Martha d'Angelo). Rio de Janeiro: Nau; Niterói: Eduff, 2010. 
SANTIAGO, Silviano. O entre-lugar do discurso latino americano. In: Por uma literatura nos trópicos: ensaios sobre dependência cultural. São Paulo: Perspectiva, 1978.

SÜSSEKIND, Flora. Cenas de fundação. In: Modernidade e modernismo no Brasil (org.: Annateresa Fabris). Campinas: Mercado de Letras, 1994. 